\title{
Construções Modais com dar no português do Brasil: metáfora, uso e gramática ${ }^{1}$
}

\author{
Modal constructions with dar in Brazilian Portuguese: \\ metaphor, usage and grammar
}

Maria Margarida Martins Salomão

UFJF/CAPES

\begin{abstract}
In this article an analysis of modal constructions with the verb "dar" in Brazilian Portuguese is proposed, based on the Goldbergian model of Construction Grammar. The results obtained point towards the treatment of grammar as a net of constructions based on usage and motivated by basilar cognitive schemata.
\end{abstract}

Keywords

Modality; Construction Grammar; Metaphor.

\section{Resumo}

Neste artigo propõe-se uma análise da família de construções modais com o verbo "dar" no português brasileiro, baseada no modelo construcionista goldbergiana. Os resultados obtidos apontam para o tratamento da gramática como rede de construções baseada no uso e motivada por esquemas cognitivamente basilares.

Palavras-chave

Modalidade; Gramática de Construções; Metáfora. 


\section{Introdução}

7 mbora não reconhecidas nem pela literatura gramatical nem pela lexicografia do Português, expressões modais com o verbo dar são vastamente familiares aos usuários contemporâneos do Português do Brasil em quaisquer das variedades abaixo ilustradas:

(1) (a) Deu prá copiar o arquivo.

(b) Não dá prá ser feliz.

(c) Dá prá eu entregar este texto mais tarde?

(2) (a) Este arquivo dá/deu prá copiar

(3) (a) O Carlos dá prá coordenar este projeto.

(b) O Carlos dá prá linguista.

(4) (a) Este dinheiro dá/deu prá gente viajar.

Todos esses usos suscitam habitualmente interpretações caracterizáveis como Modais na cartografia semântica da Modalidade proposta por van der Auwera e Plungian ( van der AUWERA; PLUNGIAN, 1998, p. 111) e geralmente aceita em estudos tipológicos e diacrônicos desta categoria linguística: usos Habilitativos em (2a), (3a/b) e (4a), Possibilitativos (na vertente Alética) em (1a/b), e Permissivos (e, nesta condição, Deônticos) em (1c).

Sintaticamente, essas expressões modais discrepam francamente entre si, desde a formação Impessoal exemplificada em (1) à formação aparentada com Tough-Movement em (2), passando pela formação aparentada com Raising em (3), até o uso em (4), que pode ser interpretado como mais uma valência lexical do verbo dar ou como uma instância das Construções Topicalizadas ilustradas por sentenças como Esta janela venta sem parar ou O Rio de Janeiro fez muito calor este fim de semana. 
A análise a ser postulada para este fascinante conjunto de casos, que identifiquei muitos anos atrás em minha tese de doutoramento (SALOMÃ̃, 1990), mas aos quais não dediquei subseqüente atenção, depende evidentemente dos compromissos teóricos que queiramos sustentar. Nas seções que se seguem, proponho uma análise construcional para as sentenças em (1). As sentenças em (2), (3) e (4) merecem um tratamento consistente com essa abordagem mas, no momento, minha análise destes casos ainda é tentativa.

Afora o interesse que pode despertar o desbravamento deste território inconquistado do Português do Brasil, argumentarei que a presente análise concorre teoricamente para o tratamento da gramática como rede de construções baseada no uso e motivada por esquemas cognitivamente basilares que se projetam metaforicamente em domínios tão abstratos quanto aqueles que constituem o mapa semântico das Modalidades.

\subsection{Pressupostos teóricos}

\subsubsection{A gramática é uma rede de Construções}

A hipótese sobre a gramática que subscrevo neste artigo corresponde a uma versão da Gramática das Construções, empreendimento teórico em desenvolvimento desde os anos oitenta do último século, sob a inspiração de George Lakoff (LAKOFF, 1987) e a liderança de Charles Fillmore e de Paul Kay (FILLMORE, 1988; FILLMORE; KAY; O'CONNOR, 1988; FILLMORE; KAY, 1993), que tem como importante representação o trabalho de Adele Goldberg (GOLDBERG, 1995; 2006) e hoje encontra endosso parcial na proposta jackendoffiana de uma arquitetura paralela para a gramática (JACKENDOFF, 2002; GOLDBERG; JACKENDOFF, 2004; CULLICOVER; JACKENDOFF, 2005). Não é meu propósito neste texto resumir ou historiar esta família de concepções (vide, para esta finalidade, Salomão, no prelo).

Alinho, abaixo, o conjunto de concepções sobre a gramática que fundamentam a presente análise:

- As unidades básicas do conhecimento linguístico e, correspondentemente, das descrições da linguagem são Construções, pareamentos de forma e significado, convencionalizados de tal modo que nenhum de seus aspectos (da forma ou do significado) sejam exclusivamente preditíveis dos elementos que os constituem. 
- Nestes termos, as Construções de uma língua dada são idiomatismos que emergem como padrões do uso, motivados cognitiva e discursivamente.

- A gramática assim concebida apresenta-se como uma rede de construções conectadas por relações de herança que não distinguem léxico e sintaxe.

Para a análise que virei a apresentar usarei a notação goldbergiana, que tem sido a mais empregada nas abordagens construcionais do Português do Brasil.

\subsubsection{As significações gramaticais, como todas as outras significações abstratas, constituem projeções figurativas dos esquemas conceptuais primários que estruturam as mais básicas experiências humanas}

Hipóteses sobre a motivação cognitiva das Construções linguísticas (alvo recorrente do ceticismo formalista) ganharam alento na última década em razão de impressionantes avanços nas ciências cognitivas, especialmente na área da neurofisiologia e da psicologia comportamental, com forte impacto em projetos de modelagem computacional da linguagem.

A consolidação desses desenvolvimentos levou, entre outros resultados, à proposição de um programa de pesquisas explicitamente inspirado pela linguística cognitiva, especialmente pela teoria conceptual da metáfora: Lakoff e Johnson (1980); Lakoff (1983); Lakoff e Johnson (1999); pela semântica de frames: Fillmore (1976, 1977, 1982, 1985); e pelos tratamentos talmyanos da semântica do movimento e da transferência de forças: Talmy (2000).

Este programa, que encontra sua expressão mais madura no livro de 2006 de Jerome Feldman, From molecule to metaphor: a neural theory of language, subsidia uma das versões correntes da Gramática das Construções, a Gramática das Construções Corporificada (Embodied Construction Grammar), representada pelos trabalhos de Dodge e Wright (2002), Chang (2005), Bergen e Chang (2005), e cujas principais hipóteses vão resumidas a seguir: 
- O pensamento abstrato se constitui a partir de experiências concretas corporificadas, tipicamente experiências somáticas e sensório-motoras.

- Os conceitos concretos são diretamente incorporados como circuitos neurais que vem a ser ativados todas as vezes em que determinado comportamento é presenciado, imaginado ou rememorado (BUCCINO et al., 2001 sobre os neurôniosespelho).

- Em consequência, a compreensão é sempre um processo de simulação mental/neural (BERGEN, 2006).

- A gênese do pensamento abstrato procede pela projeção figurativa (metafórica e metonímica) destes esquemas sensóriomotores, imagéticos e proprioceptivos que estruturam as experiências básicas dos seres humanos em sua vida e em seu convívio cotidiano (LAKOFF; JOHNSON, 1999; FELDMAN, 2006).

- Isso também se aplica à conceptualização de significações gramaticais, como a categoria linguística de Aspecto (NARANAYAN, 1997); especificamente, hipostasia-se que essas significações gramaticais sejam "cogs", isto é, estruturas resultantes do aproveitamento parcial de circuitos neurais dedicados a atividades sensório-motoras (GALLESE; LAKOFF, 2005; LAKOFF, 2006; LAKOFF, 2007).

- Em consequência, a gramática é uma rede de circuitos neurais que pareiam padrões acústico-articulatórios com esquemas conceptuais corporificados (diretamente ou figurativamente).

Esse conjunto de assertivas presume, como é óbvio, densas vinculações motivacionais na rede de heranças que constitui a gramática, em expresso desacordo com os tratamentos gramaticais hegemônicos, inclusive as abordagens construcionistas de Fillmore e Kay (1993). São, entretanto, consistentes com a análise goldbergiana das Resultativas em Inglês ( motivadas metaforicamente a partir das Construções de Movimento Causado: GOLDBERG, 1995, p.88) ou com a análise goldbergiana das Construções em Inglês de Inversão do Sujeito, estruturadas como categoria radial, ou seja, motivadas a partir de uma 
Construção básica (GOLDBERG, 2006, p.166-82).

\subsubsection{A gramática emerge como um sistema dinâmico e também nestas condições é aprendida}

O idiomatismo característico das Construções de uma língua resulta do fato de que as Construções se estabelecem como padrões do uso. Esta visão converge para a concepção emergentista da gramática como sistema dinâmico, pioneiramente esposada por Paul Hopper (HOPPER, 1988; 1998) e subscrita, de forma mais ou menos explícita, pela maioria dos estudiosos do fenômeno da gramaticalização. Também converge para a concepção "maximalista" de uma gramática-baseada-no-uso nos termos de Langacker (LANGACKER, 1988; 2000), defendida nos vários estudos coligidos em Barlow e Kemmer, 2000.

Um ponto importante dessas abordagens é o reconhecimento de que integrarão a rede da gramática tanto Construções lexicalmente abertas (por exemplo, a Construção Aplicativa em Português: Eu tanto precisando da minha secretária e ela me sai de férias) como Construções lexicalmente especificadas (por exemplo, Construções idiomáticas: chover canivete, pular carnaval; fórmulas situacionais: meus parabéns; colocações-quaseidiomatizadas: dormir no sofá, alugar carro, por a mesa), não só no nível de sua lematização mas até mesmo no nível de sua instanciação inflexional.

Essa condição permite, em termos de arquitetura da gramática, que possamos explicitar as relações de herança postuladas entre uma Construção Gramatical muito abstrata e a Construção Lexicalmente Especificada que a motiva: por exemplo,esta concepção de gramática permite-nos representar a relação que vincula a Construção Aspectual Ele anda chateado, na qual o Verbo andar está gramaticalizado como um tipo de Cópula, e a Predicação Complexa Ele anda meio inclinado para um lado, na qual o Verbo andar, que introduz a Primeira Predicação, retém sua significação básica como Verbo de Movimento.

Obviamente, este estado-da-teoria contribui para que estudos contemporâneos da gramaticalização venham recorrendo às diversas versões das Gramáticas das Construções como fundamento de suas análises (veja-se sobre esse ponto WISCHER; DIEWALD, 2002; DIEWALD, 2006). A nós interessa particularmente a motivação baseada-em-item das Construções Gramaticais, apta a explicitar a vinculação cognitiva da Construção gramaticalizada com a expressão linguística de seu domínio-fonte, tal como 
no caso, acima mencionado, da Cópula Aspectual representada pelo Verbo andar.

Uma fortíssima evidência empírica em favor dessa concepção de gramática procede das descobertas de Michael Tomasello (TOMASELLO, 1992; 2003) sobre a aprendizagem da língua materna pelas crianças.Em seu último livro (p. 140-141), Tomasello registra que, nos estágios iniciais do seu desenvolvimento, a competência linguística da criança não é caracterizável como uma "gramática", e sim como uma coleção de ilhas construcionais, relativamente isoladas e baseadas-em-itens-lexicais. Após esse período, a emergência da gramática ocorre gradualmente e de forma fragmentária, algumas Construções tornandose mais abstratas antes de outras em função das frequências-tipo e das frequências-token com que as criança as escuta. Na mesma linha, Goldberg (2006, p.85-90), identifica enviesamentos na produção linguística das crianças em função das frequências presentes na fala dos adultos, seus cuidadores.

Obviamente não se trata de advogar que o efeito frequência seja o único fator determinante da aprendizagem ou do "entrincheiramento" das Construções linguísticas: é fácil contra-exemplificar com a não-aprendizagem de seqüências que, mesmo sendo altamente freqüentes, jamais emergem como Construções; ou ainda, com a aprendizagem de expressões relativamente raras. No que diz respeito a estas últimas, Cameron-Faulkner e Kidd (2007, p.1-22), demonstram que mesmo expressões raras por razões pragmáticas (como a forma am, $1^{\text {a }}$ Pessoa do Singular do Presente do Verbo Inglês $\boldsymbol{b} \boldsymbol{e}$ ) emergem na fala da criança seguindo estritamente uma dinâmica baseada-no-uso.

De fato, os padrões que se consolidam como Construções são aqueles investidos de dimensão simbólica, encarregados de evocar cenas básicas da experência vivida e aptos, assim, a se tornarem alvo do compartilhamento da atenção dos usuários da linguagem.

\subsection{As questões}

\subsubsection{Descrição versus explicação}

É perfeitamente possível propor uma análise formal da Construção Modal Impessoal com o Verbo dar. Nossa relutância em adotar esse caminho concerne à percepção de que, se o fizéssemos, mesmo atendendo a requisitos de adequação 
descritiva, não contribuiríamos para a explicação do fenômeno considerado nem avançaríamos nosso entendimento sobre a natureza da gramática.

Por amor ao argumento, consideremos a análise que poderíamos esperar de uma teoria gramatical formal como HPSG (POLLARD; SAG, 1994; SAG et $a l, 2003)$, que tem um claro viés construcionista, pois foca as expressões linguísticas como signos, representados por matrizes de valores de traços fonológicos e sintático-semânticos, e não diferencia formações lexicais de formações sintáticas em sua hierarquia de tipos. HPSG distingue-se da abordagem que estamos preconizando por três razões principais: porque desconhece a relação de motivação como possível vinculação de herança entre Construções, porque pratica uma análise semântica absolutamente sumária e porque sua arquitetura é inteiramente refratária ao fator uso linguístico.

A Construção Modal Impessoal com o Verbo dar vai representada pela matriz, ${ }^{2}$ incluída na página seguinte.

A representação proposta ${ }^{3}$ cobre os seguintes fatos:

(i) trata-se de uma Construção Lexical do Verbo dar: não há possibilidade de substituição lexical no contexto sintático caracterizado que preserve a mesma estrutura sin-sem (isto é, o mesmo pareamento sintático-semântico);

(ii) trata-se de uma Construção Impessoal, cujo Especificador é fônica e semanticamente vazio, identificado exclusivamente pelo valor [3sg] para o traço Concordância; distingue-se da Construção com Sujeito fonicamente Nulo (Anáfora Nula) porque este último teria um conteúdo semântico indexado no traço Estrutura Argumental do Núcleo da Oração;

(iii) trata-se de uma Construção Intransitiva Preposicional (lex-vip) na qual o Complemento do Verbo dar é uma Oração Infinitiva introduzida pela Preposição para na função de Complementizador;

(iv) trata-se de uma Construção Modal que toma como domínio a proposição introduzida pela Oração Infinitiva, fato que é representado pela unificação dos Valores dos traços Índice. 


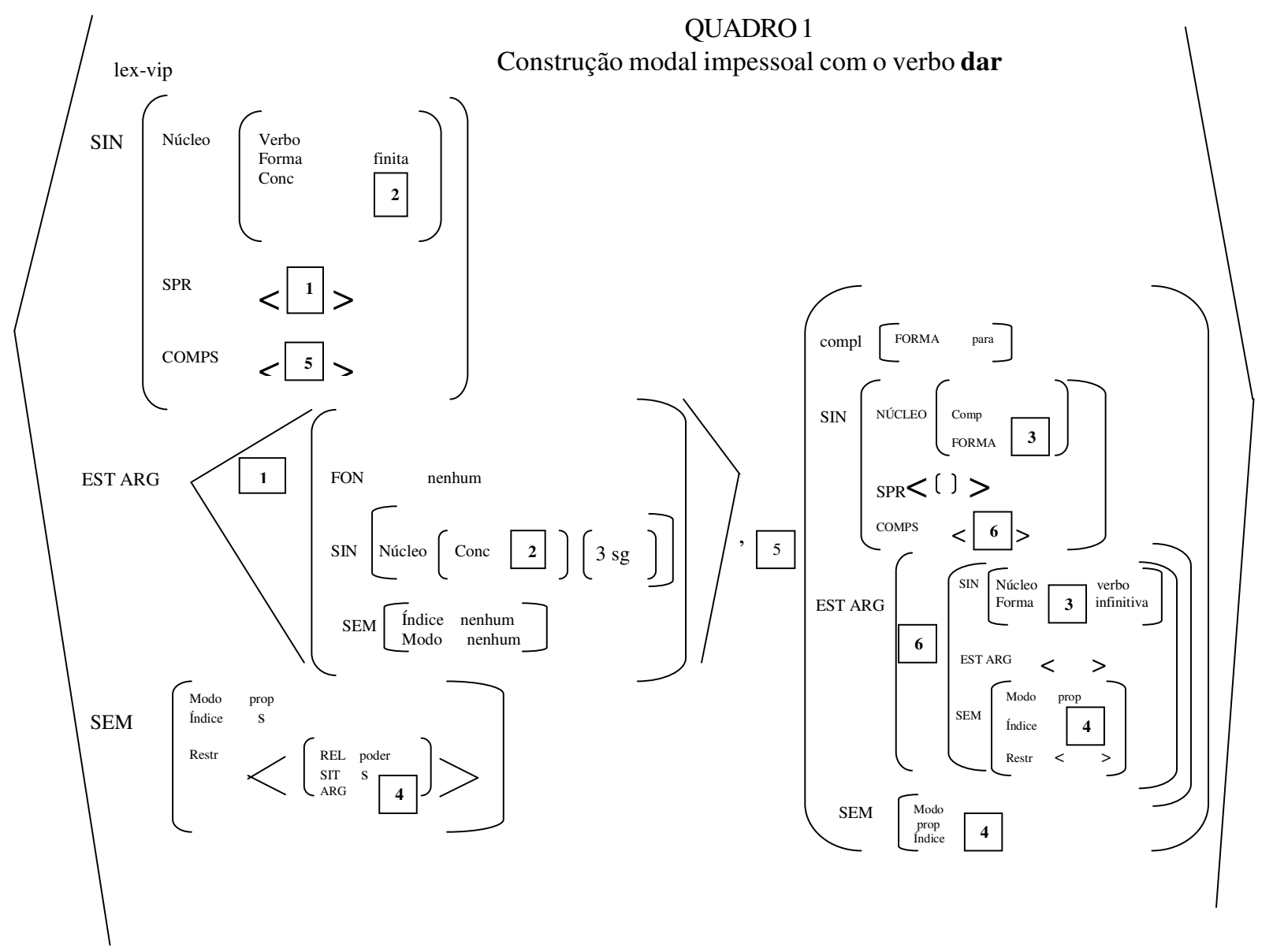


A descrição considerada encara o uso do Verbo dar na Construção como mera acidentalidade. Não há possibilidade teórica de relacioná-lo com outros usos do mesmo lexema ou, ainda, de enfrentar a Quase-Auxiliaridade (cf. HEINE, 1993, p.15) de sua participação nessa Construção: considerem-se como fatores que favorecem uma análise como Quase-Auxiliar desse lexema a circunstância de o Verbo dar ocorrer nessa Construção com sua grade temática anulada e a aproximação de seu emprego nesse caso com outros usos Modais de dar, que apresentam um Sujeito sintático "alçado" dos respectivos Complementos Infinitivos: Este arquivo dá prá copiar/O Carlos dá prá coordenar este projeto.

O fato é que as relações de herança teoricamente admitidas por HPSG presumem apenas uma especificação progressiva dos subtipos em relação a seus supertipos; nada que dê conta, por exemplo, da perda da grade temática do lexema (o que seria uma subespecificação da Construção, e não um acréscimo das restrições operativas sobre ela). Por outro lado, as Construções com "movimento" ("Raising" ou "Tough-Movement") não são nesta teoria geradas derivacionalmente (o que, aliás, me parece correto); de todo modo, nessas condições, afigura-se impossível assinalar formalmente o "parentesco" entre as várias Construções Modais consideradas.

Se, sintaticamente, a descrição proposta já se apresenta insuficiente, o valor do traço Semântica da matriz proposta é miserável: assinala exclusivamente a interpretação Modal da Construção e o escopo da Modalização introduzida (através de uma predicação modal abstrata). Não é possível sequer um detalhamento da acepção modal considerada, a qual, como veremos, pode ser ambiguamente Habilitativa, (Aleticamente) Possibilitativa ou Deôntica(Permissiva).

\subsubsection{A motivação figurativa da gramática}

A passagem diacrônica de Construções Lexicais a Construções Gramaticais recebeu enorme atenção dos estudiosos na alvorada da Linguística Cognitiva (basta lembrar o tratamento da emergência dos Modais Epistêmicos em inglês na tese de doutorado de Eve Sweetser, de 1984, publicada em Sweetser (1990, p.49-75); ou o estudo de caso apresentado em Lakoff (1987, p.462-585), sobre as Construções Locativas e Existenciais com there.)

Além disso, o mesmo tema desempenha o papel de hipótese estruturante para os estudos da gramaticalização desenvolvidos ao longo da últimas três décadas, os quais se definem como estudos “d[a mudança através da qual 
construções e itens lexicais vem a exercer funções gramaticais em determinados contextos linguísticos" (HOPPER; TRAUGOTT, 2003[1993], p.18; trad. minha).

Entre as hipóteses explicativas deste tipo de mudança linguística, destacamse especialmente o processo de metaforização (SWEETSER, 1990[1984]; 1988; BYBEE; PAGLIUCCA, 1985; HEINE; CLAUDI; HÜNNEMEYER, 1991) e o de inferenciação metonímica (BYBEE; PERKINS; PAGLIUCCA, 1994; HOPPER; TRAUGGOT, 2003[1993]; TRAUGGOT; DASHER, 2005). Nos termos de Trauggott (2006, p.113),

(...) Embora nenhum destes mecanismos invalide o outro, e se possa mesmo demonstrar que idealmente funcionam em conjunto, já que muitas metáforas se originam de metonímias (vide BARCELONA, 2000) e são plenamente operativas no contexto em que a inferenciação metonímica torna-se saliente, parece que a inferenciação metonímica é que desempenha o papel principal no processo em que falantes e ouvintes praticam a negociação do sentido e aderem à inovação; o resultado de muitas mudanças deve, entretanto, ser descrito como metáfora se se adota uma perspectiva sincrônica. (...) (Trad. e grifos meus.)

A posição mais recente de Traugott, tal como ilustrada na citação acima, parece reforçar a dimensão pragmático-conversacional da implementação dessa mudança linguística, sem, entretanto, perder de vista sua motivação cognitiva, introduzida pela metáfora conceptual na gênese e na consolidação do processo de gramaticalização.

No que nos concerne, tendo em vista a convicção que expusemos sobre o caráter emergente da gramática, é perfeitamente razoável que a fenomenologia do processo compreenda a gradual convencionalização das implicaturas suscitadas metaforicamente, processo que se dissemina progressivamente, alcançando um número cada vez maior de contextos (ou seja, de realizações lexicais). Essa situação, uma vez estabilizada, se expressará como vínculo de motivação metafórica da Construção Gramatical na rede a que pertence.

Necessário será, portanto, que a análise que viermos a propor permita representar esses fatos não apenas como explicação diacrônica, mas também como elemento fundante das heranças que constituem a rede das Construções considerada. 


\subsection{A hipótese analítica}

Considerado esse conjunto de questões e os pressupostos teóricos que lhes dizem respeito, pretendemos neste artigo mostrar que a emergência de uma específica Construção Gramatical ilustra a fundação metafórica das significações gramaticais. Pretendemos particularmente verificar que a Construção Modal Impessoal com o Verbo dar (CMI) integra uma rede construcional nucleada pela Construção de Transferência de Posse $(C T P)$ com o mesmo Verbo, de tal modo que a acepção Modal por ela suscitada procede, via Heranças Múltiplas, do mapeamento metafórico do domínio-fonte da Transferência de Forças.

\section{A rede construcional com o Verbo dar}

Como muitas outras línguas (vide o trabalho tipológico de John Newman, intitulado Give: NEWMAN, 1996), o Português apresenta um Verbo dar imensamente polissêmico; os registros lexicográficos usuais (dicionários Aurélio, Houaiss, Michaelis) consignam o respectivo verbete com mais de uma centena de acepções, listadas, é verdade, de forma redundante e desestruturada.

Em 1990, em minha tese de doutoramento (SALOMÃO, 1990), defendi, com base em argumentos praticados no escopo da Linguística Cognitiva, que esses usos interrelacionados constituíam uma categoria radial nos termos de Lakoff (1987) já que herdavam parcialmente sua sintaxe e sua semântica de uma Construção Central na rede, a Construção de Transferência de Propriedade como Verbo dar (CTP), abaixo ilustrada:

(5) O Antônio deu o livro dele prá mim.

Ainda hoje é possível sustentar esta "irradiação", postulada agora em termos mais complexos. Há dois bons motivos para isso: o primeiro é que os estudos de corpora baseados-no-uso demonstram a legitimidade da postulação de redes lexicais polissêmicas (GRIES, 2006, p.57-99) e, especificamente, de redes construcionais desenvolvidas a partir de preenchimentos lexicais (TOMASELLO, 2003; GOLDBERG, 2006). O segundoé que a versão “Corporificada" da Gramática das Construções reivindica o mapeamento de Esquemas Conceptuais Basilares (Imagéticos ou Sensório-Motores) como elementos constitutivos do significado das Construções (vide, por exemplo, BERGEN; CHANG, 2005, p. 149-153). 
O frame da Transferência de Posse suscitado pela CTP é convenientemente complexo, seja em termos dos outros frames de que é herdeiro, seja em termos de sua própria estrutura aspectual, o que explica o aproveitamento de sua expressão linguística para a evocação de tantas outras situações correlacionadas.

Além disso,é inquestionável a relevância sociocomunicativa do cenário conceptual de que se trata, o queé evidenciado não só pelo fato de que a Tranferência de Posse constitui a acepção mais freqüente nas redes polissêmicas vinculada aos lexemas traduzidos como dar nas línguas do mundo (NEWMAN, 1996), como também pelo fato de figurar essa acepção entre as mais precoces manifestações lingüísticas da criança (BLOOM, 2000; TOMASELLO, 2003).

Daí ser facilmente explicável, que a CTP venha a ser estendida como abaixo exemplificado:

(6) (a) O Antônio deu uma idéia para o título do livro.

(b) O Antônio deu um chute na porta.

(c) O Antônio deu uma dormidinha depois do almoço.

(7) (a) Esta goiabeira dá uma goiaba ótima.

(b) Aula me dá sono.

(c) Me deu fome agora.

(d) Deu sol ontem./ Deu mofo na parede.

(8) (a) O navio deu no rochedo.

(b) A rua Halfeld dá na Praça da Estação.

Não pretendo aqui retomar minha análise de 1990, mas apenas assinalar a diversidade sintática e semântica destes usos de dar (como Verbo Suporte em (6), como Causativo/Inceptivo em (7), como Verbo de Movimento (Físico ou Fictício) em (8)). Tal amostra permite, porém, imaginar como são complexas as relações de herança a partir da $C T P$, que represento a seguir, usando a notação goldbergiana de 1995 e 2006 :

CONSTRUÇÃODE TRANSFERÊNCIA DE PROPRIEDADE(CTP) (Instanciação da CONSTRUÇÃO DE MOVIMENTO CAUSADO)

$\begin{array}{cccc}\text { CAUSAR-RECEBER } & \text { AGT } & \text { TEMA } & \text { ALVO } \\ \mathrm{V} & \text { POSSUIDOR } & \text { RECURSO } & \text { RECIPIENTE } \\ d a r & \text { SUJ } & \text { OBJ } & \text { OBL/ } / \text { ra }\end{array}$


A presente representação estabelece que a Construção lexicalmente preenchida pelo Verbo dar (mas instanciável também por Verbos como entregar, outorgar, presentear, ceder, etc.) realiza sua estrutura argumental de tal forma que o Sujeito, que é tematicamente o Agente, se liga através do Elemento de Frame (EF) Possuidor ao frame Transferência de Posse, introduzido pelo lexema dar; correspondentemente, o Complemento Objeto, que é tematicamente o Tema, se liga ao mesmo frame através do EF Recurso e o Complemento Oblíquo (Preposicionado com para), que é tematicamente o Alvo, se liga ao referido frame através do EF Recipiente. A notação goldbergiana permite que representemos, por via das colunas da matriz apresentada, a unificação entre as relações temáticas constitutivas da Construção, os Elementos do Frame evocado pelo lexema e as funções gramaticais dos sintagmas que correspondem a estas indexações semânticas (Vide GOLDBERG, 1995, p.43-66.)

A notação também representa que a CTP herda da Construção de Movimento Causado a sua Valência (isto é, o pareamento de suas funções temáticas com suas funções gramaticais). A simples consideração desta interação da Valência Construcional de Movimento Causado com oframe evocado pelo lexema dar já nos assinala a íntrinseca complexidade do esquema conceptual suscitável pela $C T P$.

Além destas meta-relações semânticas, é necessário também atentar para a estrutura aspectual da Construção, caracterizável como um accomplishment, nos termos da terminologia vendleriana para classes aspectuais (VENDLER, 1967): accomplishments designam seqüências de eventos tais que o primeiro Evento, que é uma Atividade, produz um segundo Evento, que é uma Mudança de Estado como seu Resultado. O esquema conceptual complexo evocado pela CTP conflaciona Evento Causador e Evento Resultado nos termos da ligação (binding) de três esquemas conceptuais elementares:

$\begin{array}{ccccc}\text { POSSUIDOR INICIAL } & \leftarrow & \text { AGENTE } & \leftrightarrow & \text { ORIGEM } \\ \text { RECURSO } & \leftarrow & \text { PACIENTE } & \leftarrow & \text { TEMA } \\ \text { POSSUIDOR FINAL } & & \leftarrow \rightarrow & & \text { RECIPIENTE } \\ \text { RELAÇÕESDE PROPRIEDADE } & \text { AÇÃO } & & \text { TRAJETÓRIA }\end{array}$

É essa rica estrutura conceptual, pareada a uma estrutura sintática elegante e simples, que, aliada à sua alta relevância pragmática, torna a Construção de Transferência de Propriedade recurso simbólico tão poderoso. 
Se ações físicas complexas emergem da coreografia de padrões acionais primitivos (GALLESE; LAKOFF, 2005), podemos também esperar que complexos padrões interacionais (como os implicados na Tranferência de Posse) resultem da associação de estruturas conceptuais independentes. E, se sequiências motoras complexas podem ser ativadas apenas parcialmente para atender a certas determinações funcionais ( por exemplo, no caso do neurônio-espelho, a observação de uma ação requer somente a ativação de áreas pré-motoras do córtex, não a atualização de toda a sequiência requerida para o movimento), é plausível que, conceptualmente, possamos ter a evocação de conceitos abstratos através da "propagação" parcial da rede de esquemas encarregados da produção das noções mais concretas.

Desse modo, teríamos uma explicação para a gramática consistente com hipóteses empiricamente sustentadas para a explicação neurobiológica da cognição.

\section{As expressões de Modalidade na rede construcional com - Verbo dar}

\subsection{A semântica da Modalidade em termos de Transferência de Forças}

Os tratamentos tipológicos da Modalidade reservam pouco espaço para as expressões Modais baseadas em Transferência de Propriedade, não obstante elas serem encontradas em línguas com multidões de falantes como o mandarim. Além desta, outras línguas asiáticas como o lahu (falado no Laos) e o uigur (falado na parte ocidental da China) apresentam expressões Modais de Habilitação, Possibilidade (Alética) e Permissão baseadas em lexemas glossáveis como CONSEGUIR ou OBTER (BYBEE; PERKINS; PAGLIUCCA, 1994, p.188-191).

Nessa situação, como em outras, o imperialismo "linguístico" do inglês manifesta-se pela predominância de estudos sobre a Modalidade emergindo de expressões de Habilitação glossáveis como SABER (caso de can) ou como CAPACIDADE FÍSICA (caso de may / might), ou ainda como VOLIÇÃO (caso de will/would).

De todo modo, grande parte desses estudos registra como condição explicativa a hipótese talmyana sobre as significações modais (TALMY, 1988, p.53; TALMY, 2000, p. 438-452). 
Como é sabido, deve-se a Talmy um abrangente tratamento das expressões lingüísticas de Causa em termos de esquemas relativos à aplicação de Forças no domínio físico (TALMY, 1981; 1985; 1988; 2000). Tais esquemas compreendem um par de conceitos, nomeados segundo os termos que, em fisiologia, designam pares de músculos que se opõem entre si: o Agonista, que corresponde à entidadefoco da Força aplicada, e o Antagonista, que exerce a Força que se contrapõe a esta. Talmy estuda uma quantidade de situações lingüísticas em que as Forças do Agonista e do Antagonista se equilibram, ou variavelmente se sobrepujam, exercem-se continuadamente ou a partir de uma incepção abrupta, procedem à sua imposição ou a seu impedimento. Essas condições combinadas acabam por produzir uma análise bastante refinada das expressões causativas em um grande número de línguas tipologicamente distintas.

Talmy propõe que essa análise seja também aplicada para explicar as expressões lingüísticas de domínio intrapsicológico, (expressões do tipo Eu me segurei para não dizer o que eu pensava; Ela se controlou prá não brigar; etc), que constituem a classe de interações reflexivas que ele chama de psicodinâmicas. Além destas, propõe que sejam analisadas nos mesmos termos "as interações interpsicológicas entre entidades dotadas de sensibilidade e consciência, istoé, interações entre forças sociais que constituem a sociodinâmica" (TALMY, 2000, p. 438, trad. e grifos meus).

Exemplos relevantes em português dessa situação são oferecidos por sentenças como (9):

(9) (a) O assessor está sofrendo pressão do Deputado prá não abrir o bico prá Polícia Federal .

(b) Bush coagiu o Paquistão a enfrentar o Taliban.

(c) A assinatura do contrato aliviou a tensão entre os jogadores que, por isso, atuaram melhor.

(d) A gangue forçou Pixote a fazer coisas que ele não queria.

Da existência de tais relações procede a análise talmyana da Modalidade Deôntica como exercício de Forças por um Antagonista, que é uma entidade portadora de sensibilidade e consciência, sobre um Agonista, que é outra entidade da mesma classe, em termos de ser este último habilitado a agir, obrigado a agir, impedido de agir ou licenciado a agir. 
Usando os diagramas convencionais da notação talmyana, teríamos o seguinte quadro de possibilidades, ${ }^{4}$ relevante para a representação das Modalidades Deônticas: ${ }^{5}$

\section{QUADRO2}

Quadro de representação das Modalidades Deônticas em termos de esquematização de TRANSFERÊNCIA DE FORÇAS

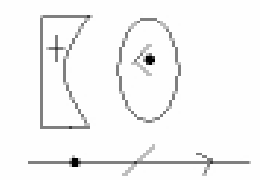

(a) ANT obriga $A G O$ a agir

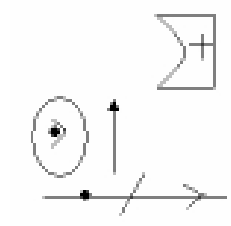

[c] ANT perrite ACO aagi

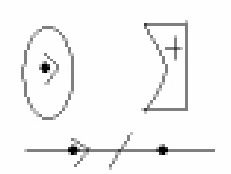

(b) $A N T$ impede $A G Q$ de agir

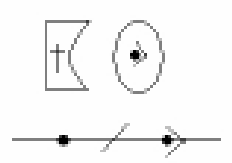

(d) ANT capacite AGOagir

Como se pode notar nesses diagramas, no que se refere à Modalidade, a Força do Antagonista é sempre superior à do Agonista: há duas situações de imposição de Força Direta contrariando a disposição do Agonista (a saber, as situações representadas por obrigar e proibir). Já no caso de licenciar/permitir, o Antagonista suspende o obstáculo à manifestação da disposição do Agonista e, no caso de capacitar/habilitar, o Antagonista transfere ao Agonista a Força que é necessária para que este realize a sua disposição.

Sweetser, em estudo clássico, explica as Modalidades Epistêmicas como projeção metafórica desses esquemas, postulados originalmente para a explicação da Modalidade Deôntica (SWEETSER, 1990, p.56-68). Nessas condições, propõe uma atraente unificação do tratamento das Modalidades em termos da projeção metafórica de esquemas conceptuais corporificados (no caso, esquemas cinestéticos: vide TALMY, 2000, p. 467). No presente artigo, assumirei esse insight sobre o tratamento das Modalidades em termos das projeções figurativas acima apresentadas. 
É clara, no caso da conceptualização de Transferência de Propriedade, a alteração sociodinâmica produzida pela atuação do Antagonista, ou seja, do Possuidor Inicial do Recurso: a obtenção de um Recurso pelo Recipiente o capacita, virtualmente, para a consecução de uma Finalidade que tenha a Posse do Recurso como Condição Necessária. Portanto, nos termos da explicação talmyana para as Modalidades Deônticas, o frame da Transferência de Propriedade afigura-se como um domínio-fonte apto para a representação metafórica de outras significações Modais.

\subsection{A conceptualização metafórica da Transferência de Recursos como Transferência de Atributos}

No caso que estamos considerando, a relação Modal envolve também as grandes metáforas ontológicas identificadas por Lakoff e Johnson (LAKOFF; JONHSON, 1999, p. 170-234) para Eventos e Causas. Os autores observam, à p.194-196, que, assim como a conceptualização da categoria de Tempo requer uma metáfora dual (o-Tempo-que-se-Move-em-Direção-ao-Observador e o-Observador-que-se-Move-no-Tempo), a conceptualização das categorias inter-relacionadas de Eventos e de Causas também requer duas metáforas: Eventos-como-Lugares e Eventos-como-Objetos.Nos termos postos à página 196, com a minha tradução,

(...) o núcleo da dualidade pode ser constatado de forma muito simples pelo seguinte contraste:

METÁFORA DA ESTRUTURA-DO-EVENTO COMO LUGAR Estados são Lugares.

Mudanças são Movimentos (para dentro ou para fora desses Lugares). Causas são Movimentos Forçados ( a partir de um Lugar ou em direção a um Lugar).

Propósitos são Destinos Desejados. (Destinações).

METÁFORA DA ESTRUTURA-DO-EVENTO COMO OBJETO Atributos são Propriedades.

Mudanças são Aquisições ou Perdas de Propriedades.

Causas são Transferências de Propriedades (dando ou recebendo).

Propósitos são Objetos desejados. (...) 
A exemplificação dessas metáforas em português é abundante, como se pode verificar em (10) (metáfora do Evento-como-Lugar) e (11) (metáfora do Evento-como-Objeto):

(10) (a) Ela está na maior animação com o novo emprego.

(b) Ela entrou no Mestrado ano passado.

(c) A economia brasileira saiu da estagnação em que se encontrava.

(d) O dólar derrubou as cotações da Bolsa.

(e) A adoção de cotas nas Universidades públicas busca um aumento de equidade no recrutamento dos alunos.

(11) (a) Estou com dor de cabeça./ Tenho esperança que a situação melhore.

(b) Perdi o sono ontem de noite./ Peguei uma antipatia desta menina!

(c) O remédio me tirou a dor completamente./ Ela me deu uma idéia muito boa para a decoração da sala.

(d) Ele tem fome de justiça. O emprego que ele está tentando é uma jóia rara. O campeão saboreou a vitória.

A Construção Modal com daré, pois, também motivada por dois específicos mapeamentos metafóricos que participam desta ontologia dual:

I. Atributos são Propriedades ( da metáfora do Evento-como-Objeto).

II.Propósitos são Destinações (da metáfora do Evento-como-Lugar).

Essas conceptualizações se combinam para projetar o complexo frame da Tranferência-de-Recursos-para-uma-Específica-Finalidade, exemplificado literalmente em (12), e, metaforicamente, em (13):

(12) (a) A Universidade pagou nossas férias ontem.

(b) Eu consegui da CAPES mais uma Bolsa para o Doutorado.

(13) (a) Ele arranjou tempo para ler o meu artigo.

(b) Preciso de arrumar paciência para lidar com esta situação.

As sentenças (12) ilustram situações em que a obtenção de um Recurso Material (pagamento da remuneração salarial destinada às férias; pagamento de bolsa para realizar estudos de pós-graduação) capacita o Recipiente a realizar um determinado Propósito. As sentenças (13) evocam o cenário em que a transferência de um Recurso metafórico (Atributos são Propriedades) suscita 
a inferência de que sua disponibilidade pelo Possuidor favorece o atingimento da pretendida Destinação metafórica, marcada pela Preposição Direcional para (Propósitos são Destinações).

A conceptualização considerada presume, comojáficou dito, a esquematização representada por (d) no Quadro 2: o Recurso Transferido é Força que capacita o Agonista a materializar a sua disposição (de mover-se ou de repousar). Como sabemos que metaforicamente Recursos são Atributos, é a Mudança metafórica, efetivada no Agonista/Recipiente pela Aquisição de novos Atributos, que o empodera a mover-se metaforicamente para a Destinação Desejada, que é o seu Propósito.

O esquema cinestético da Transferência de Forças estrutura o Cenário básico da Transferência de Propriedade, o que explica o fato de que a metáfora ontológica das Causas-como-Transferência-de-Propriedades tenha vindo a motivar a idiomatização da Modalidade Habilitativa com o Verbo dar. O ponto diferencial entre as Construções com dar e as expressões em (13) é que o Habilitado, nos casos com dar, é sempre o Recipiente metafórico de uma Doação.

\subsection{A Construção de Habilitação com o Verbo dar}

A Construção de Habilitação com o Verbo dar é uma instanciação da CTP com um Modificador que especifica a Finalidade da Transferência. Vale repetir que a Construção de Transferência de Propriedade, por ser uma Construção Causativa (de Movimento Causado), já é intrinsecamente estruturada pelo esquema conceptual da Transferência de Forças. No caso, a Força transferida é um Recurso que, virtualmente, habilitará o Recipiente a realizar o seu Propósito. Vide a ilustração literal e metafórica dessa situação em (14)(a) e (b), respectivamente:

(14) (a) A CAPES me deu uma bolsa para o Doutorado.

(b) A CAPES me deu mais tempo para apresentar o relatório.

A Construção de Habilitação diferencia-se da CTP, representada na seção 2 deste artigo, por apresentar sua Estrutura Argumental ampliada pela presença de um Modificador, que é um Objeto Oblíquo, cuja Forma pode ser a de um Sintagma Preposicional ou a de uma Oração Infinitiva, em ambos os casos introduzido pela Preposição para/prá. Em qualquer desses dois casos, o 
Modificador se unificará com a função temática Finalidade (ou Propósito), introduzida pela Construção.

Construção de Habilitação

Instanciação da Construção de Transferência de Propriedade

$\begin{array}{ccccc}\text { CAUSAR-RECEBER } & \text { AGENTE } & \text { TEMA } & \text { ALVO } & \text { FINALIDADE } \\ \mathrm{V} & \text { POSSUIDOR } & \text { RECURSO } & \text { RECIPIENTE } & \\ d a r & \text { SUJ } & \text { OBJ } & \text { OBL/ } \text { para } & \text { OBL } /_{\text {para }}\end{array}$

É interessante observar que essa Construção licencia tanto a instanciação de (15)(a) como a de (15)(b):

(15) (a) Ele deu muita força prá mim prá eu viajar.

(b) Ele deu muita força prá eu viajar.

A diferença entre essas duas possibilidades, semanticamente equivalentes, é a focalização enfática do Recipiente em (15)(a). Já em (15)(b), estamos às voltas com uma espécie de "mescla sintática" prevista por Michael Barlow (BARLOW, 2000, p. 325-329) que envolve a fusão de dois distintos lugares sintáticos, preenchidos por entidades referencialmente idênticas e conceptualmente relacionadas.

A Construção de Habilitação evoca uma acepção Modal considerada periférica no mapa semântico-discursivo de van der Auwera e Plungian (1998, p.111): trata-se de uma acepção Modal Interna-à-Proposição e Orientadapara-o-Agonista (e não para o Falante); por outro lado, a Habilitação introduzida não pode ser contada como Capacidade Inerente ao Participante/Agonista: na verdade, a Habilitação neste caso é um Fator Capacitante Circunstancial. Vale contrastar Habilitações Intrínsecas ao Agonista, como em Ele sabe nadar com Habilitações Contingentes como em $O$ salva-vidas deu prá ele uma bóia prá ele nadar na correnteza.

O significado Habilitativo dessa Construção é expresso de forma bastante precisa: a Construção somente licencia Sujeitos que correspondam a Agentes/ Causadores admissíveis ou Objetos que sejam adequadamente Habilitantes. Daí a inaceitabilidade dos exemplos (16):

(16) (a) ? A bagagem deu uma força prá eu viajar.

(b) ? O barulho me deu dor de cabeça prá eu viajar. 


\subsection{A emergência da Construção Modal Impessoal com o Verbo dar}

Nossa análise é de que a Construção Modal Impessoal com dar emerge como uma generalização da Modal Habilitativa anteriormente representada. A generalização hipostasiada se estabelece como uma progressiva ampliação dos contextos de instanciação da Construção Habilitativa, levando a correspondentes alterações na sua sintaxe e na sua semântica.

Assim, na sua instanciação "nuclear", a Construção comparece com um Agonista animado, como em (14). No entanto, a extensão figurativa de Personificação, uma das mais comuns das extensões metafóricas, logo licencia também(15):

(15) Esta estrada dá condições prá gente chegar ao Rio em duas horas.

Note-se a Instanciação Nula do Objeto Oblíquo Recipiente, catáfora do Sujeito da Infinitiva. Outras versões, semanticamente aparentadas a (15), apresentam-se como (16).

(16) (a) A estrada está boa.Dá prá gente chegar ao Rio em duas horas.

(b) Desse jeito dá prá chegar ao Rio em duas horas.

O exemplo (15) faz a asserção de uma Habilitação Circunstante produzida por uma Causa Específica (a situação da estrada). Em (16)(a), a Habilitação Circunstante é introduzida pelo contexto discursivo e figura como que anaforicamente na Construção Habilitativa em tela. Em (16)(b), no entanto, Causa e Agonista são deixados indefinidos na expressão do que já pode analisarse como uma Possibilidade Alética.

Éde destacar-se, neste último caso, a alteração semântica no caráter da Modal, que deixa de ser orientada-para-o-Agonista e adquire o caráter Avaliativo / Intersubjetivo das Modalidades gramaticalizadas (TRAUGOTT; DASHER, 2005, p.119).

A alteração semântico-sintática que ocorre nestas instanciações da Construção é radicalizada pela remoção das restrições semânticas sobre a realização sintática do Sujeito da Infinitiva, conforme se vê em (17): 
(17) (a) Dá prá ele chegar a tempo.

(b) Dá prá ele estar mais calmo agora.

(c) Dá prá ele ser derrotado na eleição.

(d) Dá prá cerveja ficar gelada até na hora do churrasco.

Nesses casos, o Sintagma que nas Habilitativas corresponde ao Agonista e, nestas condições, deveria sempre ser um Agente, apresenta-se como Agente em (17)(a), mas como Experienciador em (17)(b), como Paciente (Animado) em (17)(c) e, finalmente, como Paciente Inanimado em (17)(d). Se (17)(a-b) podem ser lidas Habilitativamente, as interpretações mais aceitáveis de (17)(c-d) são francamente Possibilitativas.

Deste modo, podemos dizer que caracterizam a Construção Modal Impessoal os seguintes fatores:

(i) a anulação das restrições semânticas sobre o Sujeito da Infinitiva (o que leva a uma ampliação das frequiências-tipo da Construção);

(ii) a Indefinição da Habilitação metaforicamente transferida;

(iii) e a Indefinição referencial do Antagonista (isto é, do Causador ou da Causa da Transferência).

É a seguinte a representação da Construção Modal Impessoal com dar:

$$
\begin{array}{cccc}
\begin{array}{c}
\text { CAUSAR-RECEBER } \\
\mathrm{V}_{\text {AUX }}
\end{array} & \text { CAUSA } & \text { POSSIBILIDADE } & \text { SITUAÇÃO } \\
\boldsymbol{d a r} & \text { SUJNULO } & \text { OBJNULO } & \text { ORAÇÃO INFINITIVA/ }
\end{array}
$$

Note-se a inespecificação da Valência lexical do Verbo dar, que deixa de contribuir o seu frame para essa Construção. Por outro lado, a estrutura argumental remanescente é a estrutura argumental construcional, constituída de uma Causa Genérica que Habilita genericamente uma Situação. Pode-se afirmar que tanto esta Causa como esta Habilitação, sintaticamente irrealizadas, procedem da Construção Lexical com dar. Esta nossa assertiva é análoga à explicação proposta por Goldberg e por Tomasello para a Construção de Estrutura Argumental Ditransitiva em Inglês como generalização da Construção Ditransitiva Lexical com o Verbo give (TOMASELLO, 2003, p. 151-154; GOLDBERG, 2006, p.77-79). 
É importante assinalar, neste ponto, a superioridade da solução construcional/ cognitivista que postulamos sobre a análise construcional formal, apresentada na metalinguagem de HPSG, na seção 1.2.1 deste artigo. Aqui, em vez de assinalarmos o valor do traço Semântica em termos de uma predicação Modal abstrata (que inespecifica a acepção Modal vinculada à Construção), representamos a significação Modal da Construção em termos da Atribuição de uma Possibilidade a uma Situação.

$\mathrm{O}$ fato de que Causas Genéricas e Possibilidades Genéricas tenham uma representação sintática nula é inteiramente consistente com o tratamento que a gramática do português reserva para Sujeitos e Objetos semanticamente Genéricos: Estão falando aí que a CPMF vai voltar (Sujeito Genérico sintaticamente Nulo); A gente come muito bem nestes quiosques da praia. (Objeto Genérico sintaticamente Nulo).

Do ponto de vista sintático, a anulação da grade temática do Verbo dar indica sua recategorização como Verbo Auxiliar ( ou Quase-Auxiliar, nos termos da distinção proposta na literatura entre Verbos (Auxiliares) que ocorrem com um Sintagma Verbal como seu Complemento e Verbos (Quase-Auxiliares) que ocorrem com um Sintagma Preposicional como seu Complemento). De todo modo, é preciso assinalar a reanálise sintática operada: passamos de uma situação com o Verbo Principal dar, nas Construções de Transferência de Posse e de Habilitação, para uma Construção Modal com o Verbo (Quase) Auxiliar dar, cuja predicação principal modalizada é realizada sintaticamente pelo Complemento Infinitivo regido da Preposição para. A análise da Construção Modal, anteriormente apresentada na notação goldbergiana, inclui esses fatos.

Outro elemento representado pelas relações de herança presentes na análise é a motivação da Construção Moda Impessoal (CMI) com dar. Antes que uma escolha lexical aleatória, condição que divergiria de toda a literatura sobre a emergência de Auxiliares Modais, a gramaticalização que descrevemos toma oframe introduzido pelo lexema dar como fator essencial no desenvolvimento da idiomatização considerada. O esquema da Transferência de Forças, constitutivo do frame da Transferência de Recursos, desempenha, como já ficou visto, papel fundamental na emergência da Construção de Habilitação e na generalização desta como $C M I$.

Cabe destacar que a emergência da $C M I$ atende a todos os requisitos indicados (TRAUGOTT; DASHER, 2005, p. 84) como traços diagnósticos de um processo de gramaticalização: 
(i) uso da Construção como perífrase especializada na expressão de uma significação tipicamente gramatical (Modal);

(ii) desbotamento da significação originária (Transferência de Recursos) do lexema e desenvolvimento de uma nova significação (Modal) para a perífrase;

(iii) convencionalização da implicatura pragmática de que a Transferência de Recurso empodera o Recipiente como Agonista de uma Finalidade virtual;

(iv) reanálise do Verbo Principal como Verbo (Quase) Auxiliar e conversão do antigo período composto em período simples;

(v) fixação da Construção;

(vi) erosão morfofonológica da Construção em usos orais representáveis como Dá preu/prele viajar amanhã.

O estudo diacrônico da emergência da CMI está por ser feito. Estudos de corpus, ainda muito preliminares, do uso desta Construção (VELLOSO, 2007) indicam não só sua juvenilidade mas também sua incidência preferencial nas modalidades oralizadas da escrita (cartas ao leitor, blogs, letras de música, MSN). Aparentemente, não há incidência atestada da Construção de Habilitação a não ser a partir do século XIX (Torrent,cp). Hoje, no entanto, os usos da CMI verificados em corpus revelam a prevalência dos usos Possibilitativos (Aléticos) e a ocorrência minoritária de usos Deônticos (Permissivos). A distribuição atestada é consistente com a tendência prevista por Bybee,Perkins e Pagliucca, (1994, p.194), abaixo representada:

\section{HABILITAÇÃO > POSSIBILIDADEALÉTICA > PERMISSÃO}

Esta tendência é ilustrada em (18):

(18) (a) Dá prá chegar ao Rio em duas horas.

(b) Dá prá chover logo de tarde.

(c) Dá prá Você esticar este deadline?

(d) Dá prá Você me dar uma mão?

A sentença (18)(a), que é (16)(a) repetida, tem, no contexto acima criado, uma ressonância Habilitativa, já bem mais esmaecida na predição metereológica em (18)(b). A sentença (18)(c) é um pedido de Permissão e (18)(d) uma 
extensão clássica das Indagações sobre Habilitação como Pedidos Indiretos de Ajuda (Você pode me passar o sal?...) Também nesse caso o processo de irradiação polissêmica confirma nossa análise da Modal.

\section{Conclusões}

Apresentamos neste artigo uma análise construcional-cognitivista da emergência de uma jovem Construção Modal no Português do Brasil, a Construção Modal Impessoal com dar (CMI).

Postulamos que essa Construção tenha emergido motivada por uma complexa rede de heranças que a vinculam metaforicamente à Construção de Transferência de Posse (CTP), Construção nuclear na categoria radial constituída pelos usos polissêmicos convencionalizados do Verbo dar em Português.

A motivação crítica nesse processo é a conceptualização metafórica da alteração sociodinâmica, introduzida pela Transferência da Propriedade de um Recurso, como Habilitação virtual de um Agonista para a consecução de uma Finalidade. Outras metáforas ontológicas (Eventos como Objetos; Causas como Aquisição/Perda de Propriedades; Finalidades como Destinações) contribuem para que situações progressivamente mais abstratas venham a ser evocadas nesses termos.

Pretendemos que a análise aqui apresentada supere outras alternativas, dentro da própria vertente construcionista, que descuram da explicitação das relações motivacionais. Por outro lado, entendemos que análises emergentistas (baseadas-no-uso e/ou focadas no estudo da gramaticalização das formas linguísticas) devem estar também comprometidas com o emprego de uma metalinguagem replicável e com a postulação de categorias teóricas consistentes. Nosso uso da notação goldbergiana busca atender esse requisito.

A presente análise requer a verificação diacrônica de sua hipótese estruturante. Sincronicamente, entretanto, as situações polissêmicas ilustradas demonstram sua exequibilidade tanto do ponto de vista sintático como do ponto de vista semântico. Sintaticamente, observa-se que a Construção corresponde a uma perífrase impessoal constituída do Verbo Quase-Auxiliar dar e de seu Complemento Infinitivo, introduzido pela Preposição para. Semanticamente, observa-se que essa perífrase modaliza como Possibilidade o domínio indexado ao Sintagma Infinitivo. 
Os exemplos considerados mostram que a emergência da acepção Modal (Possibilitativa) ocorre como generalização da acepção Habilitativa vinculada a outra Construção com dar, da qual a $C M I$ formalmente se distingue pela irrealização sintática de suas funções gramaticais.Em convergência com as predições tipológicas oferecidas na literatura, esta Construção Possibilitativa também convencionaliza sua interpretação Deôntica ( como Permissão), fato fartamente ilustrado em interações conversacionais face-a-face ou mediadas eletronicamente.

As outras Construções Modais com dar, a que aludi na primeira seção deste artigo, são prontamente analisáveis como desenvolvimentos que, na rede, herdam traços da CMI. Os detalhes desta descrição serão objeto de outro texto, que aborda toda esta família de Modais (Salomão, em preparação).

Nos termos da atual posição traugottiana, a generalização da Construção de Habilitação, obtida através do crescimento de suas frequência-tipo, passa pela convencionalização de implicatura conversacional, suscitada como inferência do mapeamento metafórico da Tranferência de Recurso em Habilitação: a saber, o Agonista, empoderado pelo(s) Atributo(s) que recebeu, torna-se virtualmente Habilitado a atingir a Finalidade que se coloque.

De todo modo, a análise apresentada constitui evidência em favor da Gramática das Construções Corporificada, uma vez que a emergência estudada, da significação Modal, é subsidiária de alteração sociodinâmica introduzida pela Transferência de Recurso de um Doador a um Recipiente, conceptualizada em termos de um esquema cinestésico (da dinâmica físico-corporal). A interpenatrabilidade aqui observada do "mundo físico"e do "mundo social" não deve nos surpreender: afinal, uma das constatações mais notáveis dos desenvolvimentos recentes nas ciências cognitivas é que o principal contexto humanoé o próprio convívio humano. 


\section{Notas}

${ }^{1}$ Partes deste trabalho, desenvolvido com o apoio da CAPES, no meu estágio como pesquisadora visitante ao Departamento de Linguística da Universidade da Califórnia, Berkeley, foram apresentadas na $33^{\text {a }}$ Reunião Anual da Berkeley Linguistics Society (fevereiro de 2007), na $10^{\mathrm{a}}$ Conferência da International Cognitive Linguistics Association (em Cracóvia, julho de 2007) e na terceira versão do Congresso Lingüística e Cognição (do GT da ANPOLL “Lingüística e Cognição”), ocorrido em agosto de 2007, em Belo Horizonte.

${ }^{2}$ As interpretrações das abreviaturas usadas são as seguintes:

lex-vip: lexema verbo intransitivo preposicionado

SIN: traço SINTAXE

CONC: traço CONCORDÂNCIA

SPR: traço ESPECIFICADOR

COMPS: traço COMPLEMENTOS

EST ARG: traço ESTRUTURA ARGUMENTAL

FON: traço FONOLOGIA

RESTR:traço RESTRIÇÕES SEMÂNTICAS

REL: traço RELAÇÃO

SIT: traço SITUAÇÃO

ARG: traço ARGUMENTO

Compl: classe sintática Complementizador

Os números dentro dos quadrados designam complexos de valores de traços e sua respectiva Unificação.

${ }^{3}$ Esta representação obedece às disposições teóricas consolidadas em Sag, Wasow e Bender (2003) mas, evidentemente, introduz inovações requeridas para a descrição de uma língua como o português, diferenciada "parametricamente"do inglês, no que admite Orações sem Sujeito. Minha solução para esse problema distingue-se da proposta de Aragão Neto (2007) por ater-se mais estritamente ao tratamento pelos autores dos “dummies"em inglês. Vale destacar que HPSG é uma teoria baseada-em-restrições, razão pela qual a descrição proposta só inclui especificações não preditíveis como herança de sua hierarquia de tipos.

${ }^{4}$ A notação talmyana representa o Agonista como um círculo, o Antagonista como a forma híbrida que se lhe antepõe, um ponto marca estado de repouso e ângulos indicam movimento. Os sinais $+\mathrm{e}-$ indicam a assimetria na distribuição de Forças. A linha inferior dividida por uma barra indica os estágios anterior e posterior à imposição (ou suspensão) da Força.

${ }^{5}$ A diagramação do esquema de Capacitação/Habilitação é proposta minha, consistente com a caracterização adotada para os demais casos. 


\section{Referências Bibliográficas}

ARAGÃO NETO, M. Análise de dirigir a partir de uma proposta de interface entre HPSG e o léxico gerativo. Working Papers em Lingüística, 2007.

BARCELONA, Antonio. On the plausibility of claiming a metonymic motivation for conceptual metaphor. In: BARCELONA, A. (Org.). Metaphor and metonymy at the crossroads. Berlin/New York: Mouton de Gruyter, 2000.

BARLOW, Michael. Usages, blends and grammar. In: BARLOW, Michael; KEMMER, Susan (Org.). Usage based models of language. Stanford: CLSI, 2000.

BERGEN, Benjamin. Experimental methods in simulation semantics. In: GONZALEZ-MARQUES, Monica; MITTELBERG, Irene; COULSON, Seana; SPIVEY, Michael (Org.). Methods in cognitive linguistics. Amsterdam/Philadelphia, 2006.

BERGEN, Benjamin; CHANG, Nancy. Embodied construction grammar in simulation-based language understanding. In: ÖSTMAN, Jan-Ola; FRIED, Mirjam (Org.). Construction grammars; cognitive grounding and theoretical extensions. Amsterdam/Philadelphia: Jonh Benjamins, 2005.

BLOOM, Paul. How children learn the meaning of words. Cambridge, Mass.: MIT Press, 2000.

BUCCINO, G. et al. Action observation activates premotor and parietal areas in a somatotopic manner: an fMRI study. European Journal of Neurosciences, n. 13, v. 2, p. 400-404, 2001.

BYBEE, Joan; PAGLIUCCA, William. Cross-linguistic comparison and the development of grammatical meaning. In: FISIAK, J. (Org.). Historical semantics: Historical word-formation. Berlin/New York: Mouton de Gruyter, 1985.

BYBEE, Joan; PERKINS, Revere; PAGLIUCCA, William. The evolution of grammar: tense, aspect and modality in the languages of the world. Chicago: Chicago University Press, 1994.

CAMERON-FAULKNER, Thea; KIDD, Evan. I'm are what I'm are: the acquisition of first-person singular present BE .Cognitive Linguistics 18-1, p. 1-22, 2007.

CHANG, Nancy. Constructing grammar: a computational model of the acquisition of early constructions.Ph.D. Thesis, University of California, Berkeley, 2005.

CULLICOVER, Peter; JACKENDOFF, Ray. Simpler syntax. New York: Oxford University Press, 2005. 
DIEWALD, Gabriele. Context types in grammaticalization as constructions. Constructions SV1-9/2006. Disponível em: www.constructions-online.de:00094-6860>. ISSN 1860-2010.

DODGE, Ellen; WRIGHT, Abby. Herds of wildebeest, flasks of vodka, heaps of trouble: an embodied construction grammar approach to English measure phrases. Proceedings of the $28^{\text {th }}$ annual meeting of the Berkeley Linguistics Society.Berkeley, Ca: University of California, Berkeley, 2002.

FELDMAN, Jerome. From molecule to metaphor; a neural theory of language. Cambridge, Mass.: The MIT Press, 2006.

FILLMORE, Charles J. Frame semantics and the nature of language.In: HARNAD, S.R. et al. (Org.). Origins and evolution of language and speech. New York: New York Academy of Sciences, 1976.

FILLMORE, Charles J. Topics in lexical semantics. In: COLE, R.W. (Org.). Current issues in linguistic theory. New York: Holt, Rinehart and Winston, 1977.

FILLMORE, Charles J. Frame semantics. In: The Linguistic Society of Korea. (Org.). Linguistics in the morning calm. Seoul: Hanshin, 1982.

FILLMORE, Charles J. Frames and the semantics of understanding. Quaderni di Semantica, 6, p. 222-254, 1985.

FILLMORE, Charles J. The mechanisms of construction grammar. Proceedings of the $14^{\text {th }}$ annual meeting of the Berkeley Linguistics Society. Berkeley: University of California, Berkeley, 1988.

FILLMORE, Charles J.; KAY, Paul. Construction grammar. Ms. University of California, Berkeley, 1993.

FILLMORE, Charles; KAY, Paul; O'CONNOR, Mary Catherine. Regularity and idiomaticity in grammatical constructions: the case of 'let alone'. Language 64, p. 501-38, 1988.

GALLESE, Vittorio; LAKOFF, George. The brain's concepts: the role of the sensory motor systems in conceptual knowledge. Cognitive Neuropsychology, v. 1, 2005.

GOLDBERG, Adele. Constructions at work. Oxford/New York: Oxford University Press, 2006.

GOLDBERG, Adele. Constructions: a construction grammar approach to argument structure. Chicago: Chicago University Press, 1995.

GOLDBERG, Adele; JACKENDOFF, Ray. The resultative as a family of constructions. Language 80, p. 532-568, 2004. 
GRIES, Stephan Th. Corpus-based methods and cognitive linguistics: the many senses of to run. In: GRIES, Stephan Th.; STEFANOWITSCH, Anatol (Org.). Corpora in cognitive linguistics. Berlin/New York: Mouton de Gruyter, 2006.

HEINE, Bernd; CLAUDI, Ulrike; HUNNEMEYER, Friederike. Grammaticalization: a conceptual framework. Chicago: University of Chicago Press, 1991.

HEINE, B. Agent-Oriented vs. Epistemic modality: some observations on German modals. In: BYBEE, Joan; FLEISCHMAN, Susan (Ed.). Modality in grammar and discourse. Amsterdam: John Benjamins, 1993.

HOPPER, Paul. Emergent grammar and the a priori grammar postulate. In: TANNEN, Deborah (Org.). Linguistics in context. Norwood, NJ: Ablex, 1988.

HOPPER, Paul. Emergent grammar. In: TOMASELLO, Michael (Org.). The new psychology of language: cognitive and functional approaches to language structure. Mahwah, NJ and London: Lawrence Erlbaum, 1998.

HOPPER, Paul; TRAUGOTT, Elizabeth [1993]. Grammaticalization. $2^{\text {nd }}$ edition. Cambridge: Cambridge University Press, 2003.

JACKENDOFF, Ray. Foundations of language. New York: Oxford University Press, 2002.

LAKOFF, George; JOHNSON, Mark. Metaphors we live by. Chicago: Chicago University Press, 1980.

LAKOFF, George. The contemporary theory of metaphor. In: ORTHONY, Andrew (Org.). Metaphor and thought. $2^{\text {nd }}$ edition substantially revised. Cambridge: Cambridge University Press, 1983.

LAKOFF, George. Women, fire and dangerous things: what categories reveal about the mind. Chicago: University of Chicago Press, 1987.

LAKOFF, George; JOHNSON, Mark. Philosophy in the flesh. New York: Basic Books, 1999.

LAKOFF, George. The neural theory of metaphor. Unpublished MS (unpaged). 2006. Disponível em: <http://hci.ucsd.edu/coulson/cogling/lakoff10.pdf>.

LAKOFF, George. The neuroscience of form in art. In: TURNER, M. (Ed.). The artful mind. Oxford/New York: Oxford University Press, 2006.

LAKOFF, George. Ten lectures on cognitive linguistics. Beijing Foreign Language Teaching and Research Press, 2007.

LANGACKER, Ronald. A usage-based model. In: RUDZKA-OSTYN, B. (Org.). Topics in cognitive linguistics. Amsterdam: John Benjamins, 1988. 
NARAYANAN, Srini. KARMA: Knowledge based active representation for metaphor and aspect. Ph.D. Dissertation.Computer Science Division. University of California, Berkeley, 1997.

NEWMAN, John. Give: a cognitive study. Berlin/ New York: Mouton de Gruyter, 1996.

POLLARD, Carl; SAG, Ivan. Head-driven phrase structure grammar. Stanford: CLSI e Chicago: University of Chicago Press, 1994.

SAG, Ivan; WASOW, Thomas; BENDER, Emily. Syntactic theory: a formal introduction. Stanford: CLSI. @ and edition, 2003.

SALOMÃO, Maria-Margarida. Polysemy, aspect and modality: the case for a cognitive explanation of grammar. Ph.D. Dissertation .Department of Linguistics. University of California, Berkeley, 1990.

SALOMÃO, Maria-Margarida. Tudo certo como dois e dois são cinco: todas as construções de uma língua. A ser publicado em 2008, pela Editora da UFMG.

SWEETSER, Eve. Grammaticalization and semantic bleaching. In: AXMAKER, S. et al. (Ed.). BLS-14.Berkeley: University of California, Berkeley, 1988.

SWEETSER, Eve. From etymology to pragmatics: metaphorical and cultural aspects of semantic structure. Cambridge: Cambridge University Press, 1990.

TALMY, Leonard. Force dynamics. Conferência apresentada ao Congresso sobre Language and Mental Imagery, em maio de 1981. Berkeley: University of California, 1981.

TALMY, Leonard. Force dynamics in language and thought. Papers from the $21^{s t}$ Regional Meeting of the Chicago Linguistic Society. Chicago: University of Chicago, 1985.

TALMY, Leonard. Force Dynamics in language and cognition. Cognitive Sciences, 12, p. 49-100, 1988.

TALMY, Leonard. Toward a cognitive semantics. Cambridge, Mass: The MIT Press, 2000. 2 v.

TOMASELLO, Michael. First verbs: a case study of early grammatical development. New York and Cambridge: Cambridge University Press, 1992.

TOMASELLO, Michael. Constructing a language: a usage based theory of language acquisition. Cambridge, Mass. and London: Harvard University Press, 2003.

TRAUGOTT, Elizabeth. Historical aspects of modality. In: FRAWLEY, William. (Ed.). The expression of modality. Berlin/New York: Mouton de Gruyter, 2006. 
TRAUGOTT, Elizabeth; DASHER, Richard. Regularity in semantic change. Cambridge: Cambridge University Press, 2005.

van der AUWERA, Johan; PLUNGIAN, Vladimir. Modality's semantic map. Linguistic Typology, 2, 1998.

VELLOSO, Monica. A emergência da gramática: estudo da idiomatização da Construção Modal com "dar" no Português do Brasil. M. A. Thesis in progress. Juiz de Fora, Brasil: UFJF, 2007.

VENDLER, Zeno. Linguistics and philosophy. Ithaca, NY: Cornell University Press, 1967.

WISCHER, Ilse; DIEWALD, Gabriele (Org.). New reflections on grammaticalization. International Symposium, Potsdam 1999. Amsterdam: John Benjamins, 2002. 